\title{
RESPON PERTUMBUHAN BIBIT ANGSANA (Pterocarpus indicus Willd.) TERHADAP MEDIA TUMBUH, PEMOTONGAN AKAR LATERAL DAN PEMBERIAN URIN SAPI
}

\author{
Response of Angsana (Pterocarpus indicus Willd.) Seedling on Growing Media, Lateral \\ Roots Cutting, and Cow's Urine
}

Hariadi Saputra, Yadi Setiadi, dan Iwan Hilwan

Departemen Silvikultur, Fakultas Kehutanan, IPB

\begin{abstract}
Nursery is a process in producing good quality seedlings. Seedling quality is determined by physical-physiological quality including woody stem, health, height, diameter, number of leaves, leaf color and compactness of media. The quality of angsana seedlings in this study was observed using some growth media, lateral root cutting, and cow's urine addition with various concentration and liquid organic fertilizer for 13 weeks. The study was conducted in a completely randomized design (CRD) in split plot with 3 growth mediums, 10 combinations of root-cutting and fertilizing treatment using 9 seedlings per treatment. Parameters observed during this study were seedling height (cm), seedling diameter $(\mathrm{mm})$, total dry weight $(\mathrm{g})$, shoot - root ratio (RPA) and compactness of roots. The results showed the media contain mixture of soil and manure (M2) with root-cutting treatment, addition of 20\% cow urine and 5\% EM4 (A2) was the best treatment for angsana seedlings with average value of $46.25 \mathrm{~cm}$ plant height, $6.09 \mathrm{~mm}$ diameter, $7.77 \mathrm{~g}$ total dry weight, shoot root ratio 1.89 and compactness of roots including the compact category.
\end{abstract}

Key word: cow's urine, lateral roots cutting, Pterocarpus indicus Willd., seedling quality.

\section{PENDAHULUAN}

Lahan kritis adalah lahan yang telah mengalami degradasi secara terus menerus sehingga kualitas tanah dan organismenya terganggu, baik bersifat sementara maupun tetap (Arsyad 2010). Luas lahan kritis di Indonesia tahun 2014 seluas \pm 24.3 juta ha (Kemenhut 2014). Rehabilitasi hutan dan lahan telah dilaksanakan oleh pemerintah untuk mengatasi lahan kritis. Namun kegiatan tersebut sering mengalami kendala dikarenakan salah satu faktornya adalah bibit sukar tumbuh dan memiliki daya hidup rendah, sehingga disamping perbaikan tanah, juga harus diimbangi dengan meningkatkan kualitas bibit agar potensi keberhasilan dalam mengatasi faktor pembatas tumbuh di lapangan meningkat (Setiadi 2002).

Kualitas bibit salah satunya ditentukan dari mutu fisik-fisiologis (Kemenhut 2009). Kriteria mutu fisikfisiologis berdasarkan Perdirjen RLPS No. P.05/VSet/2009 meliputi batang harus berkayu, tunggal dan lurus, bibit harus sehat, terbebas dari serangan hama penyakit dan warna daun normal, pertumbuhan tinggi dan diameter seimbang, media harus kompak (tidak retak, patah atau lepas). Untuk memenuhi kriteria tersebut, perlu perlakuan dan teknik silvikultur yang tepat diantaranya dengan pemilihan media tumbuh, perlakuan terhadap akar dan pemupukan.

Media tumbuh yang baik selain mengandung unsur hara juga harus memiliki drainase, aerase dan porositas yang baik pula agar dapat mendukung pertumbuhan tanaman terlebih perkembangan akar. Akar memegang peranan penting dalam pertumbuhan bibit. Bibit yang memiliki akar yang banyak cenderung memiliki pertumbuhan lebih baik dan mampu mengikat media menjadi kompak. Menurut Kartika (1997), pemotongan akar vanili dapat merangsang tumbuhnya percabangan akar-akar baru yang lebih banyak.

Pertumbuhan tanaman sangat dipengaruhi oleh ketersedian nutrisi. Ketersedian tersebut bisa berasal dari media dan luar media (pemupukan). Pemupukan sangat penting karena dapat menambah unsur-unsur hara yang dibutuhkan dalam proses pertumbuhan tanaman. Pupuk bisa berasal dari bahan anorganik (bahan kimia) dan pupuk organik (bahan alami), bisa berupa padat dan cair. Pupuk cair dari bahan organik bisa berasal dari limbah cair dari ternak berupa urin. Salah satu limbah cair dari ternak tersebut yang sering dimanfaatkan adalah urin sapi.

Urin sapi selain memiliki kandungan unsur utama $\mathrm{N}$, $\mathrm{P}$, dan $\mathrm{K}$ juga mengandung auksin yang berfungsi sebagai perangsang akar sehingga dapat menggantikan fungsi hormon tumbuh (Supriadji 1985). Selain dari urin sapi, pupuk cair dari bahan organik juga banyak dijual di pasaran telah dikemas dalam bentuk pupuk organik cair (POC). POC selain dapat memperbaiki sifat fisik, kimia, dan biologi tanah, juga membantu meningkatkan produksi dan kualitas produk tanaman, mengurangi penggunaan pupuk anorganik dan sebagai alternatif pengganti pupuk kandang (Parman 2007).

Penelitian ini bertujuan untuk ; (1) Menguji respon pertumbuhan bibit angsana di rumah kaca pada beberapa media setelah diberi perlakuan pemotongan 
akar lateral dan pemupukan. (2) Menganalisis bentuk kekompakan media dan akar dari bibit angsana setelah diberikan perlakuan. (3) Menentukan kualitas mutu bibit angsana pada umur 3 bulan.

\section{METODE PENELITIAN}

\section{Waktu dan Tempat Penelitian}

Penelitian dilakukan di Rumah Kaca Divisi Ekologi Hutan Departemen Silvikultur Fakultas Kehutanan Institut Pertanian Bogor selama 5 bulan. Penelitian ini dilaksanakan pada bulan Oktober 2016 sampai dengan Maret 2017. Analisis media dilakukan di Laboratorium Tanah Departemen Ilmu Tanah dan Sumberdaya Lahan Fakultas Pertanian IPB.

\section{Prosedur Kerja}

\section{Persiapan benih dan media semai}

Benih angsana yang digunakan sebelumnya direndam dengan air panas selama \pm 30 menit kemudian air dingin selama \pm 12 jam untuk mempercepat proses kecambah benih (Lensari 2009). Media yang digunakan berupa pasir yang telah diayak.

\section{Persiapan pupuk dan pemupukan}

Pembuatan pupuk cair urin sapi dalam penelitian ini dibuat dengan tiga konsentrasi yaitu $20 \%, 20 \%+5 \%$ EM4 dan 50\%. Larutan yang telah dibuat dimasukkan dalam jerigen ukuran 30 liter dan ditambahkan larutan molasses/gula sebesar 5\% per liter. Larutan molasses/gula dibuat dengan perbandingan gula pasir dan air 1:1. Larutan molasses mengandung karbohidrat tinggi (64\%) yang diperlukan jasad renik sehingga dapat meningkatkan kecepatan proses produksi pengolahan urin sapi menjadi pupuk dalam waktu relatif singkat yaitu 14 hari (Wijaya 2008).

Penambahan Effective Microorganism 4 atau EM4 pada salah satu konsentrasi pupuk cair 20\% dalam penelitian ini bertujuan mempercepat proses pengomposan dari 3 bulan menjadi 7-14 hari dengan memberi tambahan mikroba terpilih seperti Lactobacillus sp, bakteri penghasil asam laktat, bakteri fotosintetik, Streptomyces dan ragi yang bekerja secara sinergik dalam proses dekomposisi (Wididana \& Higa 1993).

Selain urin sapi, dalam penelitin ini juga menggunakan pupuk organik cair (POC) yang dijual di pasaran. Konsentrasi POC yang diberikan sebesar $8 \mathrm{~mL}$ (sesuai aturan pemakaian) dilarutkan dalam 1 liter air dan diberikan ke masing-masing polybag sebanyak 50 $\mathrm{mL}$. Dosis urin sapi yang diberikan secara bertahap dengan dosis $25 \mathrm{~mL}$ pada pemupukan pertama dan kedua serta $50 \mathrm{~mL}$ pada pemupukan ketiga sampai ketujuh. Hal ini didasarkan pada pra penelitian awal yang dilakukan dengan dosis $100 \mathrm{~mL}$ dan $75 \mathrm{~mL}$ membuat tanaman layu dan mati.

\section{Persiapan media dan penyapihan bibit}

Media tumbuh tanah yang digunakan dalam penelitian ini berasal dari belakang resimen mahasiswa
IPB dengan jenis tanah adalah ultisol. Media tumbuh yang digunakan disesuaikan dengan kapasitas polybag yang berukuran L $12 \times$ P $20 \mathrm{~cm}$. Media tumbuh yang digunakan $600 \mathrm{~g}$ tanah, $400 \mathrm{~g}$ pupuk kandang, $525 \mathrm{~g}$ campuran tanah dan pupuk kandang (tanah $350 \mathrm{~g}$ dan pupuk kandang $175 \mathrm{~g}$ ). Penyapihan bibit dilakukan pada saat bibit berumur 3 minggu.

Bibit yang digunakan baik yang dipotong akarnya maupun tidak, sebelum dilakukan penyapihan dicelupkan ke masing-masing konsentrasi pupuk $( \pm 15$ detik) untuk memberi stimulus (merangsang) pertumbuhan serabut-serabut akar agar lebih banyak dan lebih panjang. Jumlah akar yang dipotong disesuaikan dengan banyaknya akar pada bibit. Panjang akar dipotong $\pm 0.2 \mathrm{~cm}$ sampai $0.4 \mathrm{~cm}$ dari ujung akar untuk mencegah stres pada bibit dan menjaga agar penyerapan unsur hara pada bibit tetap berjalan baik.

\section{Parameter pengamatan}

Parameter yang diamati dan diukur selama 13 minggu yaitu tinggi bibit $(\mathrm{cm})$ dan diameter bibit $(\mathrm{mm})$, dilakukan setiap 15 hari. Parameter yang diukur pada saat panen yaitu bobot kering akar/BKA (g), bobot kering pucuk/BKP(g), bobot kering total/BKT (g), rasio pucuk akar/RPA dan kekompakan akar. Kekompakan akar ditentukan secara deskriptif dengan melihat akar pada media saat polybag dilepas. Status kompak jika akar sudah keluar dan tidak kompak jika belum keluar.

\section{Rancangan percobaan}

Penelitian dilakukan di rumah kaca dengan menggunakan rancangan acak lengkap (RAL) dengan petak terbagi (split plot design) yang terdiri dari petak utama dan anak petak. Petak utama yaitu media tanah (M0), media pupuk kandang (M1), campuran media tanah dan pupuk kandang (M2). Anak petak terdiri atas 10 kombinasi perlakuan yaitu potong akar (A0), potong akar $+20 \%$ urin sapi (A1), potong akar $+20 \%$ urin sapi $+5 \%$ EM4 (A2), potong akar $+50 \%$ urin sapi (A3), potong akar + POC (A4), tidak potong akar (A5), tidak potong akar $+20 \%$ urin sapi (A6), tidak potong akar + $20 \%$ urin sapi $+5 \%$ EM4 (A7), tidak potong akar + $50 \%$ urin sapi (A8), tidak potong akar + POC (A9). Tiap kombinasi perlakuan diulang sebanyak 3 kali dan masing-masing ulangan memiliki unit sebanyak 3 .

Analisis data menggunakan sidik ragam atau anova pada taraf 5\% untuk melihat perbedaan antar perlakuan. Uji Duncan pada taraf 5\% dilakukan apabila terjadi pengaruh beda nyata perlakuan terhadap peubah yang diamati (Mattjik \& Sumertajaya 2006). Pengolahan data menggunakan program SAS 9.1.3.

\section{HASIL DAN PEMBAHASAN}

\section{Analisis NPK pada Media Tanam}

Ketersediaan unsur hara makro berupa nitrogen, fosfor, dan kalium (NPK) pada media tumbuh sangat penting untuk mendukung pertumbuhan. Kandungan hara tersebut mempengaruhi ketersediaan nutrisi yang dapat diakses oleh akar tanaman sehingga menentukan pertumbuhan bibit angsana. Nilai $\mathrm{C} / \mathrm{N}$ rasio yang tinggi 
menunjukkan proses penguraian oleh mikroorganisme pada media masih berjalan sehingga dapat menghambat pertumbuhan bibit. Tabel 1 menunjukkan hasil analisis kandungan hara dari masing-masing media tumbuh bibit angsana.

Hasil analisis media pupuk kandang (M1) memiliki kandungan air sebesar $76.93 \%$. Kondisi ini mempengaruhi pertumbuhan tanaman dikarenakan masih menunjukkan proses penguraian dan pelepasan amoniak. Kadar air pupuk kandang yang ideal sebagai media tumbuh tidak lebih dari $35 \%$ sehingga jika lebih akan menghambat pertumbuhan tanaman karena masih menunjukkan proses penguraian oleh mikroorganisme (FFTC 1997). Untuk itu masih memerlukan waktu pengomposan lagi.

Status hara media menurut Hardjowigeno (2003), media tanah (M0) memiliki $\mathrm{N}$ rendah, $\mathrm{P}$ sangat rendah, $\mathrm{K}$ sedang, C-org sangat rendah. Media pupuk kandang (M1) N sangat tinggi, $\mathrm{P}$ sangat tinggi, $\mathrm{K}$ sangat tinggi, C-org sangat tinggi. Media pencampuran tanah dan pupuk kandang (M2) N tinggi, $\mathrm{P}$ sangat tinggi, $\mathrm{K}$ sangat tinggi, C-org sangat tinggi. Pada media M1 memiliki ketersedian nutrisi yang sangat tinggi namun belum bisa dimanfaatkan maksimal dikarenakan masih memiliki kadar air tinggi (kadar air maksimal 35\%) yang menunjukkan proses penguraian (dekomposisi) oleh mikroorganisme masih berjalan.

Tabel 2 Hasil rekapitulasi analisis sidik ragam perlakuan terhadap peubah yang diamati

\begin{tabular}{|c|c|c|c|}
\hline \multirow{2}{*}{ Peubah } & \multicolumn{2}{|c|}{ Perlakuan } & \multirow{2}{*}{ Interaksi } \\
\hline & Petak utama & Anak petak & \\
\hline $\begin{array}{l}\text { Tinggi } \\
(\mathrm{cm})\end{array}$ & $*$ & * & $*$ \\
\hline $\begin{array}{l}\text { Diameter } \\
(\mathrm{mm})\end{array}$ & $*$ & $*$ & * \\
\hline $\mathrm{BKT}(\mathrm{g})$ & $*$ & $*$ & $*$ \\
\hline
\end{tabular}

Ket : $*$ berpengaruh nyata pada taraf $5 \%$.

Hasil sidik ragam pada Tabel 2 menunjukkan bahwa semua peubah yang diamati dan diukur berbeda nyata terhadap media tanam, pemotongan akar dan pemupukan serta interaksi antara dua perlakuan tersebut. Hasil uji Duncan pada tiap peubah disajikan sebagai berikut:
Tabel 3 Hasil uji Duncan pengaruh petak utama terhadap peubah yang diamati

\begin{tabular}{lccc}
\hline \multirow{2}{*}{\multicolumn{1}{c}{ Peubah }} & \multicolumn{3}{c}{ Petak utama } \\
\cline { 2 - 4 } & M0 & M1 & M2 \\
\hline Tinggi (cm) & $15.4^{\mathrm{b}}$ & $9.6^{\mathrm{c}}$ & $18.4^{\mathrm{a}}$ \\
Diameter (mm) & $3.12^{\mathrm{b}}$ & $2.82^{\mathrm{c}}$ & $3.62^{\mathrm{a}}$ \\
BKT (g) & $1.88^{\mathrm{b}}$ & $1.66^{\mathrm{b}}$ & $3.78^{\mathrm{a}}$ \\
\hline
\end{tabular}

Ket: huruf yang sama pada baris yang sama tidak berbeda nyata pada selang kepercayaan $95 \%$.

Hasil uji Duncan pada Tabel 3 menunjukkan bahwa semua peubah pada perlakuan M2 berbeda nyata dibandingkan dengan perlakuan lainnya. Perlakuan $\mathbf{M}_{2}$ memiliki nilai tertinggi dibandingkan dengan perlakuan $\mathrm{M}_{0}$ dan $\mathrm{M}_{1}$. Persentase peningkatan peubah $\mathrm{M} 2$ terhadap M0 dan M1 secara berturut-turut sebesar $19.48 \%$ dan $91.67 \%$ pada peubah tinggi, $16.03 \%$ dan $28.37 \%$ pada peubah diameter, $101.06 \%$ dan $127.71 \%$ pada peubah bobot kering total (BKT).

Tanaman akan tumbuh subur apabila segala unsur yang dibutuhkannya tersedia dan terdapat dalam bentuk yang sesuai untuk diserap tanaman (Supriyanto \& Fiona 2010). Pupuk kandang sebagai media tumbuh cocok karena memiliki kandungan unsur hara yang lengkap seperti Nitrogen $(\mathrm{N})$, fosfor $(\mathrm{P})$, dan kalium $(\mathrm{K})$. Selain itu, pupuk kandang memiliki kandungan mikroorganisme yang mampu merombak bahan organik yang sulit dicerna tanaman menjadi komponen yang lebih mudah untuk diserap tanaman.

Hasil uji Duncan pada Tabel 4 menunjukkan bahwa semua peubah perlakuan akar dan pemupukan pada perlakuan A2 berbeda nyata dengan perlakuan lainnya. Hal ini dikarenakan dengan pemotongan akar mampu memperbanyak tumbuhnya akar-akar baru sehingga memperbanyak dan memudahkan proses penyerapan nutrisi oleh tanaman. Penambahan EM4 sebesar 5\% dalam urin sapi $20 \%$ pada perlakuan potong akar (A2) memberikan pengaruh dan hasil yang lebih baik dibandingkan dengan hanya $20 \%$ urin sapi pada perlakuan potong akar (A1) dan perlakuan lainnya. Penambahan ini mampu mempercepat proses pengomposan dan meningkatkan kualitas urin dikarenakan dalam urin yang ditambahkan EM4 memiliki mikroba-mikroba terpilih dan unggul.

Tabel 1 Analisis kandungan NPK media tumbuh bibit angsana

\begin{tabular}{lcllccr}
\hline \multirow{2}{*}{ Media } & \multicolumn{7}{c}{ Unsur } \\
\cline { 2 - 6 } & $\mathrm{N}(\%)$ & $\mathrm{P}(\%)$ & $\mathrm{K}(\%)$ & $\mathrm{C}-$ org $(\%)$ & Kadar air $(\%)$ & C/N Ratio $(\%)$ \\
\hline M0 & 0.13 & 0.000496 & 0.01326 & 0.74 & - & 5.69 \\
M1 & 1.15 & 2.20000 & 0.3200 & 31.78 & 76.93 & 27.63 \\
M2 & 0.70 & 0.008505 & 0.05772 & 7.09 & - & 10.13 \\
\hline
\end{tabular}

Ket:, N = Nitrogen, P = Fosfor, K = Kalium, C-org = Carbon organik

Tabel 4 Hasil uji Duncan pengaruh anak petak terhadap peubah yang diamati

\begin{tabular}{|c|c|c|c|c|c|c|c|c|c|c|}
\hline \multirow{2}{*}{ Peubah } & \multicolumn{10}{|c|}{ Anak petak } \\
\hline & $\mathrm{A}_{0}$ & $\mathrm{~A}_{1}$ & $\mathrm{~A}_{2}$ & $\mathrm{~A}_{3}$ & $\mathrm{~A}_{4}$ & $\mathrm{~A}_{5}$ & $\mathrm{~A}_{6}$ & $\mathrm{~A}_{7}$ & $\mathrm{~A}_{8}$ & $\mathrm{~A}_{9}$ \\
\hline Tinggi $(\mathrm{cm})$ & $12.1^{\mathrm{d}}$ & $18.1^{\mathrm{ab}}$ & $21.0^{\mathrm{a}}$ & $16.5^{b}$ & $15.4^{b c}$ & $11.9^{\mathrm{d}}$ & $12.8^{\mathrm{cd}}$ & $12.8^{\mathrm{cd}}$ & $8.3^{\mathrm{e}}$ & $15.7^{\mathrm{bc}}$ \\
\hline Diameter (mm) & $3.22^{\mathrm{bcd}}$ & $3.49^{\mathrm{ab}}$ & $3.89^{\mathrm{a}}$ & $3.50^{\mathrm{ab}}$ & $3.34^{\mathrm{bc}}$ & $2.88^{\mathrm{d}}$ & $3.00^{\mathrm{cd}}$ & $3.00^{\mathrm{cd}}$ & $2.46^{\mathrm{e}}$ & $3.14^{\mathrm{bcd}}$ \\
\hline $\mathrm{BKT}(\mathrm{g})$ & $2.50^{\text {cde }}$ & $3.07^{\mathrm{bc}}$ & $4.04^{\mathrm{a}}$ & $3.17^{\mathrm{b}}$ & $2.63^{\mathrm{bcd}}$ & $1.80^{\mathrm{fgh}}$ & $1.64^{\mathrm{gh}}$ & $1.98^{\text {efg }}$ & $1.24^{\mathrm{h}}$ & $2.32^{\mathrm{def}}$ \\
\hline
\end{tabular}

Ket : huruf yang sama pada baris yang sama tidak berbeda nyata pada selang kepercayaan $95 \%$. 


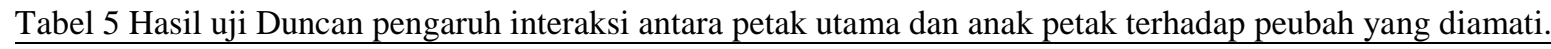

\begin{tabular}{|c|c|c|c|c|}
\hline \multirow{3}{*}{ Peubah } & \multicolumn{4}{|c|}{ Interaksi } \\
\hline & \multirow{2}{*}{ Anak Petak } & \multicolumn{3}{|c|}{ Petak Utama } \\
\hline & & $\mathrm{M}_{0}$ & $\mathrm{M}_{1}$ & $\mathrm{M}_{2}$ \\
\hline \multirow[t]{10}{*}{ Tinggi } & $\mathrm{A}_{0}$ & $13.3^{\text {defgh }}$ & $6.1^{i}$ & $17.1^{\mathrm{def}}$ \\
\hline & $\mathrm{A}_{1}$ & $15.3^{\text {defg }}$ & $11.0^{\text {fghi }}$ & $25.8^{\mathrm{b}}$ \\
\hline & $\mathrm{A}_{2}$ & $19.8^{\mathrm{cd}}$ & $9.9^{\text {ghi }}$ & $33.3^{\mathrm{a}}$ \\
\hline & $\mathrm{A}_{3}$ & $14.0^{\mathrm{defgh}}$ & $10.5^{\text {fghi }}$ & $25.0^{\mathrm{bc}}$ \\
\hline & $\mathrm{A}_{4}$ & $15.9^{\text {defg }}$ & $14.1^{\text {defgh }}$ & $17.7^{\mathrm{de}}$ \\
\hline & $\mathrm{A}_{5}$ & $13.2^{\text {defgh }}$ & $7.8^{\text {hi }}$ & $13.7^{\text {defgh }}$ \\
\hline & $\mathrm{A}_{6}$ & $15.2^{\text {defg }}$ & $11.1^{\text {efghi }}$ & $12.0^{\text {efghi }}$ \\
\hline & $\mathrm{A}_{7}$ & $13.2^{\text {defgh }}$ & $9.3^{\text {ghi }}$ & $15.9^{\text {defg }}$ \\
\hline & $\mathrm{A}_{8}$ & $11.3^{\text {efghi }}$ & $5.5^{\mathrm{i}}$ & $9.5^{\text {ghi }}$ \\
\hline & $\mathrm{A}_{9}$ & $19.7^{\mathrm{cd}}$ & $10.3^{\text {ghi }}$ & $17.1^{\mathrm{def}}$ \\
\hline \multirow[t]{10}{*}{ Diameter } & $\mathrm{A}_{0}$ & $3.24^{\text {defgh }}$ & $2.81^{\text {efghijk }}$ & $3.56^{\text {bcde }}$ \\
\hline & $A_{1}$ & $3.27^{\mathrm{defgh}}$ & $3.04^{\text {defghijk }}$ & $4.18^{\mathrm{b}}$ \\
\hline & $\mathrm{A}_{2}$ & $3.52^{\text {bcdef }}$ & $2.85^{\text {efghijk }}$ & $5.15^{\mathrm{a}}$ \\
\hline & $\begin{array}{l}\mathrm{A}_{2} \\
\mathrm{~A}_{3}\end{array}$ & $3.26^{\mathrm{defgh}}$ & $2.85^{\text {efghijk }}$ & $4.03^{\mathrm{bc}}$ \\
\hline & $\mathrm{A}_{4}$ & $3.29^{\mathrm{defgh}}$ & $3.12^{\text {defghi }}$ & $3.66^{\text {bcd }}$ \\
\hline & $A_{5}$ & $3.09^{\text {defghij }}$ & $2.32^{\mathrm{jk}}$ & $3.26^{\mathrm{defgh}}$ \\
\hline & $\begin{array}{l}\mathrm{A}_{5} \\
\mathrm{~A}_{6}\end{array}$ & $2.98^{\text {defghijk }}$ & $2.96^{\text {defghijk }}$ & $2.92^{\text {defghijk }}$ \\
\hline & $\mathrm{A}_{7}$ & $2.82^{\text {efghijk }}$ & $2.72^{\text {ghijk }}$ & $3.38^{\text {cdefg }}$ \\
\hline & $\mathrm{A}_{8}$ & $2.38^{\mathrm{ijk}}$ & $2.29^{\mathrm{k}}$ & $2.58^{\mathrm{hijk}}$ \\
\hline & $\mathrm{A}_{9}$ & $3.37^{\text {cdefg }}$ & $2.75^{\text {fghijk }}$ & $3.24^{\mathrm{defgh}}$ \\
\hline \multirow[t]{10}{*}{$\overline{B K T}$} & $\mathrm{~A}_{0}$ & $2.15^{\text {efghij }}$ & $1.91^{\text {fghij }}$ & $3.43^{\mathrm{cd}}$ \\
\hline & $\mathrm{A}_{1}$ & $1.91^{\text {fghij }}$ & $2.01^{\text {fghij }}$ & $5.31^{b}$ \\
\hline & $\mathrm{A}_{2}$ & $2.64^{\text {cdefg }}$ & $1.69^{\text {fghij }}$ & $7.78^{\mathrm{a}}$ \\
\hline & $\mathrm{A}_{3}$ & $1.88^{\text {fghij }}$ & $1.65^{\text {fghij }}$ & $5.98^{\mathrm{b}}$ \\
\hline & $\mathrm{A}_{4}$ & $1.94^{\text {fghij }}$ & $2.23^{\text {efghi }}$ & $3.72^{\mathrm{c}}$ \\
\hline & $A_{5}$ & $1.69^{\text {fghij }}$ & $0.99^{\mathrm{j}}$ & $2.73^{\text {cdef }}$ \\
\hline & $\mathrm{A}_{6}$ & $1.38^{\mathrm{hij}}$ & $1.86^{\text {fghij }}$ & $1.66^{\text {fghij }}$ \\
\hline & $\mathrm{A}_{7}$ & $1.25^{\mathrm{ij}}$ & $1.48^{\text {ghij }}$ & $3.19^{\text {cde }}$ \\
\hline & $\mathrm{A}_{8}$ & $1.17^{\mathrm{ij}}$ & $1.07^{\mathrm{j}}$ & $1.49^{\text {ghij }}$ \\
\hline & $\mathrm{A}_{9}$ & $2.76^{\text {cdef }}$ & $1.72^{\text {fghij }}$ & $2.47^{\text {defgh }}$ \\
\hline
\end{tabular}

Ket :huruf yang sama pada kolom peubah yang sama tidak berbeda nyata pada selang kepercayaan $95 \%$.

Hasil uji Duncan pada Tabel 5 menunjukkan bahwa semua peubah pada perlakuan interaksi M2A2 berbeda nyata dengan perlakuan lainnya. Hal ini dikarenakan pada interaksi M2A2 kandungan unsur haranya seimbang, struktur medianya gembur dan remah dibandingkan interaksi lain. EM4 yang dicampurkan pada urin sapi mampu mengurai bahan organik dengan bantuan mikroba-mikroba terpilih (Lactobacillus $\mathrm{sp}$, bakteri fotosintetik, actinomycetes, Streptomyces dan ragi/yeast) sehingga kombinasi antara tanah, pupuk kandang, urin sapi 20\% + EM4 5\% (M2A2) menghasilkan bibit yang berkualitas.

Pada Tabel 5 peubah tinggi, diameter dan BKT tertinggi terdapat pada M2A2 dengan nilai tinggi 33.3 $\mathrm{cm}$ dengan kenaikan $152.21 \%$, diameter $5.15 \mathrm{~mm}$ dengan kenaikan $66.67 \%$ dan BKT 7.78 dengan kenaikan 360.35\% dibandingkan dengan kontrol M0A5.

Media tumbuh berupa tanah memiliki keterbatasan unsur hara didalamnya. Hal ini sesuai dengan pernyataan Hardjowigeno (2003) bahwa semakin ke lapisan bawah tanah kandungan bahan organiknya semakin berkurang sehingga tanah semakin kurus/miskin hara. Penggunaan pupuk organik seperti kotoran sapi sebagai bahan tambahan campuran tanah pada saat penanaman dapat menambah zat-zat hara didalam tanah yang dibutuhkan tanaman untuk pertumbuhan sehingga dapat menyuplai unsur hara yang dibutuhkan dan memperbaiki struktur tanah (Junaidi et al. 2013).

\section{Rasio Pucuk Akar (RPA)}

Tabel 6 Hasil rekapitulasi rasio pucuk akar (RPA) ratarata bibit angsana yang diberi perlakuan.

\begin{tabular}{cccc}
\hline \multirow{2}{*}{ Perlakuan } & \multicolumn{3}{c}{ Media } \\
\cline { 2 - 4 } & $\mathrm{M}_{0}$ & $\mathrm{M}_{\mathrm{I}}$ & $\mathrm{M}_{2}$ \\
\hline $\mathrm{A}_{0}$ & 1.50 & 1.79 & 1.74 \\
$\mathrm{~A}_{1}$ & 1.82 & 1.83 & 1.92 \\
$\mathrm{~A}_{2}$ & 1.93 & 1.81 & 1.89 \\
$\mathrm{~A}_{3}$ & 1.88 & 1.91 & 1.79 \\
$\mathrm{~A}_{4}$ & 1.74 & 1.97 & 1.81 \\
$\mathrm{~A}_{5}$ & 1.94 & 1.76 & 1.75 \\
$\mathrm{~A}_{6}$ & 1.81 & 1.98 & 1.76 \\
$\mathrm{~A}_{7}$ & 1.58 & 1.69 & 1.83 \\
$\mathrm{~A}_{8}$ & 1.85 & 1.74 & 1.67 \\
$\mathrm{~A}_{9}$ & 1.81 & 1.75 & 1.75 \\
\hline
\end{tabular}

Ket: $\mathrm{M} 0=$ Media Tanah, M1 = Media Pupuk Kandang, M2 = Media Tanah + Pupuk Kandang, A0 = Potong Akar, A1 $=$ Potong Akar $+20 \%$ urin sapi, $\mathrm{A} 2=$ Potong Akar + $20 \%$ urin sapi $+5 \%$ EM4, A3 $=$ Potong Akar $+50 \%$ urin sapi, A4 $=$ Potong Akar + POC, A5 = Tidak Potong Akar, A6 $=$ Tidak Potong Akar $+20 \%$ urin sapi, A7 $=$ Tidak Potong Akar $+20 \%$ urin sapi $+5 \%$ EM4, A8 = Tidak Potong Akar $+50 \%$ urin sapi, A9 $=$ Tidak Potong Akar + POC

Tabel 6 merupakan rasio pucuk akar (RPA) yaitu perbandingan antara berat kering akar dengan berat kering pucuk. Bibit dinilai siap dan layak tanam apabila nilai RPA ada pada kisaran 2-5 (Mindawati \& Yusnita 2005). Menurut Departemen Kehutanan dan Perkebunan (1999) dalam Petunjuk Mutu Bibit Hutan Tanaman 
Industri (HTI) bahwa bibit yang memenuhi syarat tanam adalah bibit dengan tinggi 10-40 cm, nisbah akar : pucuk $=1: 1$ atau 1:2, kayu di sekitar leher akar keras, tajuk simetris, dan sistem perakaran padat. Tabel 6 ratarata dari parameter rasio pucuk akar menunjukkan bahwa bibit angsana pada semua media M0, M1 dan M2 memenuhi syarat bibit siap dan layak tanam.

\section{Kekompakan Akar}

Kekompakan akar menjadi salah satu parameter yang perlu dinilai secara deskriptif untuk menentukan kualitas bibit yang akan dipindahkan ke lapangan. Status kompak jika akar sudah keluar dari media tanam dan tidak kompak jika akar belum keluar dari media tanam. Tabel 7 menunjukkan kekompakan media dan akar masing- masing perlakuan. Kekompakan akar sangat berhubungan dengan kemampuan bibit dalam menyerap unsur hara yang tersedia pada media tumbuh. Semakin kompak perakaran bibit maka pertumbuhannya semakin baik.

Tabel 7 Analisis deskriptif kekompakan akar pada beberapa media, perlakuan potong akar dan pemupukan.

\begin{tabular}{|c|c|c|c|c|c|c|}
\hline \multirow{3}{*}{$\begin{array}{l}\text { Perla- } \\
\text { kuan }\end{array}$} & \multicolumn{6}{|c|}{ Media } \\
\hline & \multicolumn{2}{|c|}{$\mathrm{M}_{\mathrm{O}}$} & \multicolumn{2}{|c|}{$\mathrm{M}_{\mathrm{I}}$} & \multicolumn{2}{|c|}{$\mathrm{M}_{2}$} \\
\hline & $\begin{array}{c}\text { Kom- } \\
\text { pak }\end{array}$ & $\begin{array}{c}\text { Tidak } \\
\text { Kom- } \\
\text { pak }\end{array}$ & $\begin{array}{c}\text { Kom- } \\
\text { pak }\end{array}$ & $\begin{array}{c}\text { Tidak } \\
\text { Kom- } \\
\text { pak }\end{array}$ & $\begin{array}{c}\text { Kom- } \\
\text { pak }\end{array}$ & $\begin{array}{c}\text { Tidak } \\
\text { Kom- } \\
\text { pak }\end{array}$ \\
\hline A0 & & $\checkmark$ & & $\checkmark$ & $\checkmark$ & \\
\hline A1 & & $\checkmark$ & & $\checkmark$ & $\checkmark$ & \\
\hline A2 & $\checkmark$ & & & $\checkmark$ & $\checkmark$ & \\
\hline A3 & $\checkmark$ & & & $\checkmark$ & $\checkmark$ & \\
\hline A4 & $\checkmark$ & & & $\checkmark$ & $\checkmark$ & \\
\hline A5 & & $\checkmark$ & & $\checkmark$ & $\checkmark$ & \\
\hline A6 & & $\checkmark$ & & $\checkmark$ & & $\checkmark$ \\
\hline A7 & & $\checkmark$ & & $\checkmark$ & $\checkmark$ & \\
\hline A8 & & $\checkmark$ & & $\checkmark$ & & $\checkmark$ \\
\hline A9 & $\checkmark$ & & & $\checkmark$ & $\checkmark$ & \\
\hline
\end{tabular}

Ket: M0 $=$ Media Tanah, M1 = Media Pupuk Kandang, M2 = Media Tanah + Pupuk Kandang, A0 = Potong Akar, A1 $=$ Potong Akar $+20 \%$ urin sapi, A2 = Potong Akar + $20 \%$ urin sapi $+5 \%$ EM4, A3 $=$ Potong Akar $+50 \%$ urin sapi, $\mathrm{A} 4=$ Potong Akar $+\mathrm{POC}, \mathrm{A} 5=$ Tidak Potong Akar, A6 $=$ Tidak Potong Akar $+20 \%$ urin sapi, A7 = Tidak Potong Akar $+20 \%$ urin sapi $+5 \%$ EM4, A8 = Tidak Potong Akar $+50 \%$ urin sapi, A9 $=$ Tidak Potong Akar + POC

Media tumbuh berupa campuran tanah dan pupuk kandang (M2) sangat berpengaruh terhadap parameter kekompakan akar. Dari 10 kombinasi perlakuan, hanya 2 perlakuan yang secara deskriptif terlihat belum memiliki kekompakan akar yang baik. Ini lebih baik dibandingkan M0 yang hanya memiliki 4 dan M1 yang keseluruhan kombinasinya belum memiliki kekompakan akar yang baik. Perlakuan potong akar dan kombinasinya menghasilkan bibit yang lebih baik dibandingkan tidak potong akar. Hal ini dikarenakan dengan pemotongan akar dapat memperbanyak tumbuhnya akar-akar baru yang akan memudahkan penyerapan hara sehingga pertumbuhan tanaman lebih baik lagi.
Jenis tanah yang digunakan adalah tanah ultisol yang pada umumnya memiliki sifat kurus/miskin hara. Sehingga pemberian pupuk kandang pada tanah dapat memperbaiki struktur tanah. Hal ini dapat terjadi karena penguraian bahan organik oleh organisme dalam pupuk bersifat sebagai pelekat dan dapat mengikat butir-butir tanah menjadi butiran yang lebih besar sehingga diharapkan sifat fisik dan kimia tanah dapat diperbaiki. Pemberian pupuk kandang juga dapat membuat tanah menjadi ringan, daya ikat air menjadi tinggi, daya ikat tanah terhadap unsur hara meningkat, serta drainase tanah dapat diperbaiki (Musnawar 2003). Hal ini akan mendukung perkembangan akar sehingga mampu mengikat media menjadi kompak.

\section{KESIMPULAN}

1. Media campuran tanah dan pupuk kandang (M2) merupakan media tumbuh terbaik bibit angsana umur 13 minggu dengan nilai tinggi $18.4 \mathrm{~cm}$, diameter $3.62 \mathrm{~mm}$, berat kering total (BKT) $3.78 \mathrm{~g}$.

2. Perlakuan potong akar dan pemberian urin sapi $20 \%$ + 5\% EM4 (A2) merupakan perlakuan terbaik bibit angsana umur 13 minggu dengan nilai tinggi $21.0 \mathrm{~cm}$, diameter $3.88 \mathrm{~mm}$, berat kering total (BKT) $4.04 \mathrm{~g}$.

3. Media campuran tanah dan pupuk kandang dengan potong akar dan pemberian urin sapi $20 \%+5 \%$ EM4 (M2A2) merupakan perlakuan terbaik bibit angsana umur 13 minggu dengan nilai tinggi 33.3 $\mathrm{cm}$, diameter $5.15 \mathrm{~mm}$, berat kering total (BKT) $7.78 \mathrm{~g}$.

4. Media dan akar yang kompak rata-rata ditunjukkan pada media pencampuran tanah dan pupuk kandang (M2) sebanyak 8 perlakuan.

5. Kualitas mutu bibit terbaik terdapat pada campuran media tanah dan pupuk kandang, dengan perlakuan potong akar dan pemberian urin sapi $20 \%+5 \%$ EM4 (M2A2).

\section{SARAN}

1. Penggunaan media tanah dan pupuk kandang dengan perlakuan pemberian urin sapi $20 \%$ dan 5\% EM4 dapat dijadikan acuan perlakuan dalam menghasilkan bibit angsana yang berkualitas.

2. Kualitas bibit angsana terbaik hasil penelitian perlu dilakukan uji lanjut di lapangan untuk melihat konsistensi respon pertumbuhan baik di rumah kaca maupun di lapangan .

\section{DAFTAR PUSTAKA}

Arsyad S. 2010. Konservasi Tanah dan Air $2^{\text {nd }}$. Bogor (ID). IPB Press.

Departemen Kehutanan dan Perkebunan. 1999. Panduan Kehutanan Indonesia. Departemen Kehutanan dan Perkebunan. Jakarta.

[FFTC]Food Fertilizer Technology Center. 1997. Quality control for organic fertilizer. News 
letter 117. Food and Fertilizer Tehnology Center, Taiwan, ROC.

Hardjowigeno S. 2003. Ilmu Tanah. Akademika Pressindo. Jakarta

Junedi H, Mahbub IA, Zurhalena. 2013. Pemanfaatan Kompos Kotoran Sapi dan Ara Sungsang untuk Menurunkan Kepadatan Ultisol. Jurnal Penelitian Universitas Jambi Seri Sains vol 15, No 1, Hal. 47-52.

Kartika NH. 1997. Pengaruh Pemotongan Akar dan Sifat Fisik, Media Tanam terhadap Pertumbuhan Stek Panili (Vanilla planifolia Andrews). [Skripsi]. Bogor (ID). Institut Pertanian Bogor.

[Kemenhut] Kementerian Kehutanan. 2009. Peraturan Menteri Kehutanan Nomor:P.05/V-Set/2009 Tentang Pedoman Pengujian Mutu Bibit Tanaman Hutan. Jakarta (ID): Kemenhut.

[Kemenhut] Kementerian Kehutanan. 2014. Statistik Direktorat Jenderal BPDASPS. Jakarta (ID): Kemenhut.

Lensari D. 2009. Pengaruh Pematahan Dormansi terhadap Kemampuan Perkecambahan Benih Angsana. [Skripsi]. Bogor (ID). Institut Pertanian Bogor.

Mattjik AA, Sumertajaya IM. 2006. Perancangan Percobaan dengan Aplikasi SAS dan Minitab. Bogor (ID). IPB Press.

Musnawar. 2003. Pengaruh Pemberian Bahan Organik Terhadap Sifat-Sifat Tanah. Jurnal Ilmu Tanah dan Lingkungan.
Mindawati N,Yusnita S. 2005. Pengaruh Macam Media terhadap Pertumbuhan Semai Acacia mangium Willd. Jurnal Penelitian Hutan dan Konservasi Alam 2(1):53-59. Pusat Penelitian dan Pengembangan Hutan dan Konservasi Alam. Bogor.

Parman S. 2007. Pengaruh Pemberian Pupuk Organik Cair terhadap Pertumbuhan dan Produksi Kentang (Solanum tuberosum L.). Buletin Anatomi dan Fisiologi Vol. XV, No. 2.

Setiadi Y. 2002. Peranan mikoriza arbuskula dalam rehabilitasi lahan kritis di Indonesia. Prosiding Seminar Nasional Mikoriza. Asosiasi Mikoriza Indonesia Cabang Jawa Barat.

Supriadji G. 1985. Air Kemih Sapi sebagai Perangsang Stek Kopi. Warta Penelitian dan Pengembangan Pertanian 7(2): 11-12.

Supriyanto, Fiona F. 2010. Pemanfaatan arang sekam untuk memperbaiki pertumbuhan Semai Jabon (Anthocephalus cadamba (Roxb.) Miq) pada media subsoil. Jurnal Silvikultur TropikaVol. 01. 01:24-28.

Wididana GN, Higa T. 1993. Effectif Effective Microorganism4 $\left(\mathrm{EM}_{4}\right)$ on Growth and Production of Crops. Bulletin Kyusei Nature Farming.

Wijaya KA. 2008. Nutrisi Tanaman sebagai Penentu Kualitas Hasil dan Resistensi Alami pada Tanaman. Jakarta: Prestasi Pustaka. 